\title{
Expert System To Identify Insomnia Problems In Adults Using Forward Chaining Method
}

\section{Sistem Pakar Untuk Mengidentifikasi Masalah Insomnia Pada Orang Dewasa Menggunakan Metode Forward Chaining}

\author{
Ayu Dwi Ratna Ningsih ${ }^{1}$, Ade Eviyanti \\ \{ayud6439@gmail.com ${ }^{1}$, adeeviyanti@umsida.ac.id ${ }^{2}$ \}
}

Universitas Muhammadiyah Sidoarjo, Jl. Raya Gelam No. 250 Sidoarjo. 61271 Indonesia

\begin{abstract}
Insomnia is a symptom that is often experienced by adults of productive age, such as having difficulty starting to sleep, often waking up at night. With the development of technology, most of the jobs have involved technology. Expert systems are artificial intelligence that is growing rapidly in the world of technology. With an expert system, a person can be helped according to their needs when it is difficult to meet directly with the expert. The purpose of this study was to make it easier for researchers to identify insomnia problems based on the symptoms experienced by the adults around them. The research method used is the forward chaining method. while the data collection technique is quantitative data technique. The desired result of this study is the reduction of a person affected by insomnia problems and the Expert System can provide solutions to reduce Insomnia Problems such as relaxation music before consulting a doctor.
\end{abstract}

Keywords - Insomnia; Forward Chaining; Expert System

\begin{abstract}
Abstrak. Insomnia adalah gejala yang sering kali dialami oleh orang dewasa diusia produktif seperti memiliki kesulitan untuk memulai tidur, sering terbangun di malam hari. Dengan perkembangan teknologi, sebagian besar pekerjaan telah melibatkan teknologi. Sistem pakar adalah kecerdasan buatan yang berkembang pesat di dunia teknologi. Dengan sistem pakar, seseorang dapat terbantu sesuai dengan kebutuhannya ketika sulit untuk bertemu langsung dengan pakar tersebut. Tujuan penelitian ini adalah untuk memudahkan peneliti dalam mengidentifikasi masalah insomnia berdasarkan gejala yang dialami oleh orang dewasa disekitarnya. Metode penelitian yang diguanakan ialah Metode forward chaining. sedangkan teknik pengumpulan datanya yaitu teknik data kuantitatif. Hasil yang diinginkan dari penelitian ini adalah pengurangan seseorang yang terkena masalah insomnia dan Sistem Pakar dapat memberikan solusi untuk mengurangi Masalah Insomnia seperti musik relaksasi sebelum berkonsultasi dengan dokter.
\end{abstract}

Kata Kunci - Insomnia; Forward Chaining; Sistem Pakar

\section{Pendahuluan}

Pada beberapa orang sering mengalami adanya gangguan tidur. Salah satu gangguan tidur yang sering dialami oleh orang dewasa khusunya pada mahasiswa Universitas Muhammadiyah Sidoarjo adalah Insomnia, dimana individu memiliki cukup kesempatan untuk tidur tetapi individu mengalami kesulitan untuk memulai tidur dan menjaga pola tidur yang baik.

Dewasa awal adalah masa-masa usia produktif dimana sangat berisiko terkena insomnia. Puncak produktivitas dewasa awal seseorang terjadi pada usia $21-40$ tahun baik dari segi kognitif ataupun fisik. Peran sebagai mahasiswa memiliki resiko besar terkena insomnia yaitu penurunan kesehatan mental yang diakibatkan oleh stres karena adanya tekanan akademik dan permasalahan pribadi lainnya. Perpindahan pola dari mahasiswa ke bekerja juga perlu disesuaikan. Seperti kebiasaan mahasiswa yang fleksibel dan dunia kerja yang teratur, maka kebiasaan tidur seperti begadang juga harus dikontrol.

Untuk mengidentifikasi bahwa seseorang tersebut mengalami masalah jenis insomnia apa, maka diperlukan konsultasi terkait permasalahan tersebut ke dokter atau pakarnya. Dengan adanya permasalahan tersebut guna membantu user / pasien dalam hal memudahkan konsultasi dan mengetahui solusi untu meredam penyakit insomnia, maka penulis memiliki ide untuk membuat "Sistem Pakar untuk Mengidentifikasi Masalah Insomnia Pada Orang Dewasa menggunakan Metode Forward Chaining" Semoga dengan adanya sistem aplikasi ini dapat membantu user/pasien dalam mengidentifikasi masalah insomnia yang dideritanya. Yang menurut saya masalah Insomnia ini bukan masalah sepele dikarenakan sangat mempengaruhi aktivitas di pagi harinya. 


\section{METODE}

\section{A. Tahap pengumpulan data}

Teknik pengumpulan data pada penelitian ini diantaranya membaca buku dan jurnal yang terkait dengan topik penelitian yang diambil, kedua metode pengumpulan data dengan mengisi pertanyaan yang sudah dipersiapkan sebelumnya dan wawancara dengan pakar, ketiga observasi dengan cara mengamati langsung.

\section{B. Subyek dan obyek penelitian}

Dalam penelitian ini subyek yang digunakan adalah mahasiswa Universitas Muhammadiyah Sidoarjo dan masyarat umum, sedangkan obyek dari penelitian ini adalah seorang pakar yang mengerti dan memahami dalam hal penyakit insomnia.

\section{Teknik analisis masalah}

Masalah gangguan insomnia pada seseorang merupakan kategori dari masalah Artificial Inteligent, atau bisa disebut dengan sistem pakar[5]. Untuk memecahkan masalah tersebut dilakukan dengan mengembangkan sistem yang dapat berperan sebagai seorang ahli atau seorang pakar[8]. Hal ini disebut knowledge engineering (penyerapan basis pengetahuan dari seorang pakar ke sebuah komputer) .

\section{Kerangka penelitian}

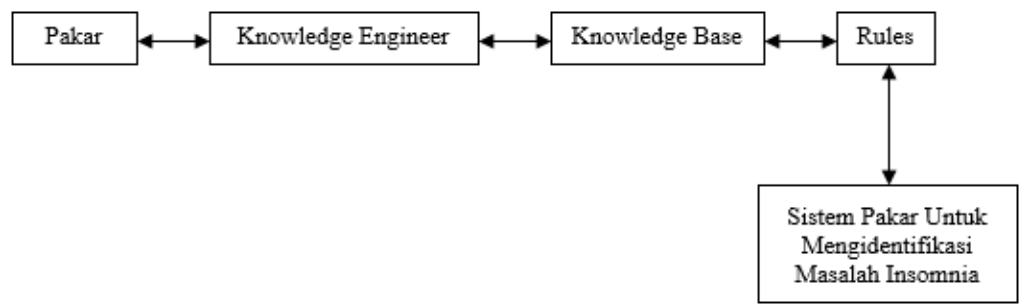

Gambar 1. Tahapan penelitian

Knowledge Engineer disini digunakan untuk mendapatkan pengetahuan mengenai gejala-gejala insomnia dari seorang pakar $^{[2]}$. Setelah itu informasi yang didapat dikumpulkan untuk dikodekan ke programmer dan hasilnya dituangkan dalam Knowledge Base dan diolah untuk menjadi sebuah rules ${ }^{[1]}$. dari knowledge engineer dan knowledge base dapat menghasilkan Aplikasi sistem pakar yang digunakan oleh user untuk Mengidentifikasi masalah insomnia ${ }^{[3]}$.

Tabel 1. Gejala Insomnia

\begin{tabular}{lll}
\hline No. & Kode tes & \\
\hline 1. & G01 & Saya memiliki kesulitan untuk memulai tidur \\
2. & G02 & Saya lebih peka terhadap kebisingan \\
3. & G03 & Saya sering merasa lelah dan tidak bertenaga saat bangun \\
4. & G04 & Saya menderita gangguan sakit kepala dan gangguan pernafasan \\
5. & G05 & Saya meminum alkohol untuk membantu tidur \\
6. & G06 & Saya memiliki gangguan kesehatan yang mengganggu tidur \\
7. & G07 & Saya merasa tidak bersemangat melakukan aktivitas dan hobi \\
8. & G08 & Saya merasa sedih, mudah tersinggung, atau putus harapan \\
9. & G09 & Saya selalu merasa gugup atau khawatir akhir-akhir ini \\
10. & G10 & Saya merasa tubuh anda sedang dalam kondisi tidak baik \\
11. & G11 & Saya bekerja di malam hari atau memiliki jadwal tidur yang berubah-rubah \\
12. & G12 & Kaki saya tida dapat berhenti bergerak dan atau merasa tidak nyaman sebelum tidur \\
13. & G13 & Saya kecanduan kafein pada kopi \\
14. & G14 & Saya sering terbangun di malam hari \\
15. & G15 & Saya kurang berolahraga \\
16. & G16 & Saya mengidap gangguan kecemasan \\
17. & G17 & Saya susah untuk tidur kembali \\
18. & G18 & Saya merasa setres terhadap sesuatu hal \\
19. & G19 & Saya merasakan sakit ditulang punggung jika pada saat kondisi dingin \\
20 & G20 & Saya sulit untuk tetap terjaga dari tidur \\
\hline
\end{tabular}


Dari gejala yang dialami akan menghasilkan konklusi (kesimpulan akhir) atau bisa disebut juga dengan hasil identifikasi. Jenis insomnia yang akan teridentifikasi pada penelitian ini ada 6 jenis yaitu Insomnia kronis, insomnia akut, insomnia temporer, insomnia temporer, insomnia psychophysiological, insomnia komorbid, dan insomnia primer. Metode yang digunakan pada penelitian ini adalah metode forward chaining, yang dimulai dari premis atau fakta untuk menuju hasil identifikasi atau kesimpulan akhir sebagai pengambil keputusannya ${ }^{[6]}$.

Tabel 2. Identifikasi Insomnia

\begin{tabular}{|c|c|c|}
\hline No. & Kode hasil & Kriteria \\
\hline 1. & I001 & Insomnia Kronic \\
\hline 2. & I002 & Insomnia Akut \\
\hline 3. & I003 & Insomnia Temporer \\
\hline 4. & I004 & Insomnia Psychophysiologicalt \\
\hline 5. & I005 & Insomnia Komorbid \\
\hline 6. & I006 & Insomnia Primer \\
\hline
\end{tabular}

Dari hasil identifikasi tabel 2, langkah selanjutnya rule pakar akan terbentuk seperti tabel 3 berikut ini :

Tabel 3. Rule Pakar

\begin{tabular}{cccc}
\hline No. & Kode Rule & Kode Gejala & Nama penyakit \\
\hline 1. & Rule 1 & $\mathrm{G} 01, \mathrm{G} 03, \mathrm{G} 06, \mathrm{G} 07, \mathrm{G} 08, \mathrm{G} 09, \mathrm{G} 10, \mathrm{G} 11$ & Insomnia Kronic \\
2. & Rule 2 & $\mathrm{G} 01, \mathrm{G} 03, \mathrm{G} 06, \mathrm{G} 07, \mathrm{G} 08, \mathrm{G} 09, \mathrm{G} 10$ & Insomnia Kronic \\
3. & Rule 3 & $\mathrm{G} 01, \mathrm{G} 03, \mathrm{G} 06, \mathrm{G} 07, \mathrm{G} 08, \mathrm{G} 09$ & Insomnia Kronic \\
4. & Rule 4 & $\mathrm{G} 01, \mathrm{G} 03, \mathrm{G} 06, \mathrm{G} 07, \mathrm{G} 08$ & Insomnia Kronic \\
5. & Rule 5 & $\mathrm{G} 01, \mathrm{G} 03, \mathrm{G} 06, \mathrm{G} 07$ & Insomnia Kronic \\
6. & Rule 6 & $\mathrm{G} 01, \mathrm{G} 03, \mathrm{G} 06$ & Insomnia Kronic \\
7. & Rule 7 & $\mathrm{G} 01, \mathrm{G} 03$ & Insomnia Kronic \\
8. & Rule 8 & $\mathrm{G} 01, \mathrm{G} 02, \mathrm{G} 03, \mathrm{G} 06, \mathrm{G} 19$ & Insomnia Akut \\
9. & Rule 9 & $\mathrm{G} 01, \mathrm{G} 02, \mathrm{G} 03, \mathrm{G} 06$ & Insomnia Akut \\
10. & Rule 10 & $\mathrm{G} 01, \mathrm{G} 02, \mathrm{G} 03$ & Insomnia Akut \\
11. & Rule 11 & $\mathrm{G} 01, \mathrm{G} 02$ & Insomnia Akut \\
12. & Rule 12 & $\mathrm{G} 01, \mathrm{G} 05, \mathrm{G} 13, \mathrm{G} 14$ & Insomnia Temporer \\
13. & Rule 13 & $\mathrm{G} 01, \mathrm{G} 05, \mathrm{G} 13$ & Insomnia Temporer \\
14. & Rule 14 & $\mathrm{G} 01, \mathrm{G} 05$ & Insomnia Temporer \\
15. & Rule 15 & $\mathrm{G} 01, \mathrm{G} 15, \mathrm{G} 16, \mathrm{G} 18$ & Insomnia Psychophysiologicalt \\
16. & Rule 16 & $\mathrm{G} 01, \mathrm{G} 15, \mathrm{G} 16$ & Insomnia Psychophysiologicalt \\
17. & Rule 17 & $\mathrm{G} 01, \mathrm{G} 15$ & Insomnia Psychophysiologicalt \\
18. & Rule 18 & $\mathrm{G} 01, \mathrm{G} 04, \mathrm{G} 06, \mathrm{G} 12$ & Insomnia Komorbid \\
19. & Rule 19 & $\mathrm{G} 01, \mathrm{G} 04, \mathrm{G} 06$ & Insomnia Komorbid \\
20. & Rule 20 & $\mathrm{G} 01, \mathrm{G} 04$ & Insomnia Komorbid \\
21. & Rule 21 & $\mathrm{G} 01, \mathrm{G} 17, \mathrm{G} 20$ & Insomnia Primer \\
22. & Rule 22 & $\mathrm{G} 01, \mathrm{G} 17$ & Insomnia Primer \\
\hline
\end{tabular}

keputusan pakar pada tabel 4 ini terbentuk dari gejala insomnia dan rule pakar.

Tabel 4. Keputusan Pakar

\begin{tabular}{|c|c|c|c|c|c|c|c|}
\hline \multirow[t]{2}{*}{ No. } & \multirow[t]{2}{*}{ Kode Gejala } & \multicolumn{6}{|c|}{ Insomnia } \\
\hline & & Kronis & Akut & Temporer & Psychophysiologicalt & Komorbid & Primer \\
\hline 1. & G01 & $\mathrm{X}$ & $\mathrm{X}$ & $\mathrm{X}$ & $\mathrm{X}$ & $\mathrm{X}$ & $\mathrm{X}$ \\
\hline 2. & G02 & & $\mathrm{X}$ & & & & \\
\hline 3. & G03 & $\mathrm{X}$ & $\mathrm{X}$ & & & & \\
\hline 4. & G04 & & & & & $\mathrm{X}$ & \\
\hline 5. & G05 & & & $\mathrm{X}$ & & & \\
\hline 6. & G06 & $X$ & X & & & $X$ & \\
\hline 7. & G07 & $X$ & & & & & \\
\hline 8. & G08 & $\mathrm{X}$ & & & & & \\
\hline 9. & G09 & $X$ & & & & & \\
\hline 10. & G10 & $\mathrm{X}$ & & & & & \\
\hline 11. & G11 & $X$ & & & & & \\
\hline
\end{tabular}


Procedia of Engineering and Life Science Vol. 1. No. 2 Juni 2021

Seminar Nasional \& Call Paper Fakultas Sains dan Teknologi (SENASAINS 2 ${ }^{\text {nd }}$ )

Universitas Muhammadiyah Sidoarjo

12. G12

13. G13

14. G14

15. G15

16. G16

17. G17

18. G18

19. G19

$20 \quad$ G20
$\mathrm{X}$

$\mathrm{X}$

$\mathrm{X}$

$\mathrm{X}$

$\mathrm{X}$
$\mathrm{X}$

$\mathrm{X}$

$\mathrm{X}$

\section{Hasil Dan Pembahasan}

\section{A. Perancangan Sistem}

Use case diagram

Pada gambar ini menggambarkan kelakuan sistem yang akan dibuat. Pemodelan ini menjelaskan bahwa sistem pakar dapat melakukan manager data sampai memberikan solusi yang dialami user melalui gejala gejala yang dideritanya dan User akan mendapatkan hasil identifikasi sesuai gejala yang dialami.

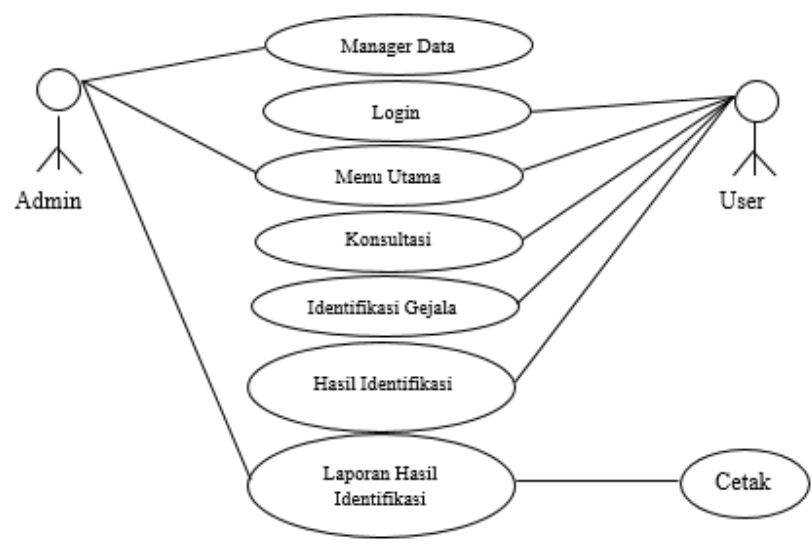

Gambar 3. Use Case Diagram

Activity diagram

Pada gambar ini menjelaskan tentang aktivitas user/pengguna. Mulai dari halaman home, pengguna akan memilih gejala sesuai dengan yang dialami . Lalu sistem melakukan identifikasi gejala yang dialami user

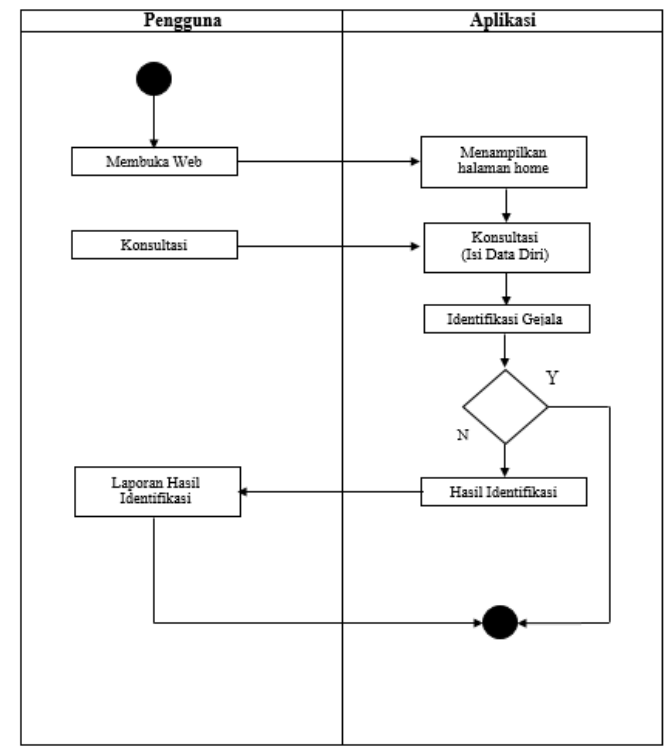

Gambar 4. Activity Diagram 
Procedia of Engineering and Life Science Vol. 1. No. 2 Juni 2021

Seminar Nasional \& Call Paper Fakultas Sains dan Teknologi (SENASAINS 2 ${ }^{\text {nd }}$ )

Universitas Muhammadiyah Sidoarjo

Sequence diagram

Pada gambar sequence diagram ini menjelaskan hubungan user dengan sistemnya. User akan memulai dengan isi data diri untuk masuk ke sistem. Dan sistem akan menampilkan hasil identifikasi insomnia apa yang diderita sekaligus solusinya.

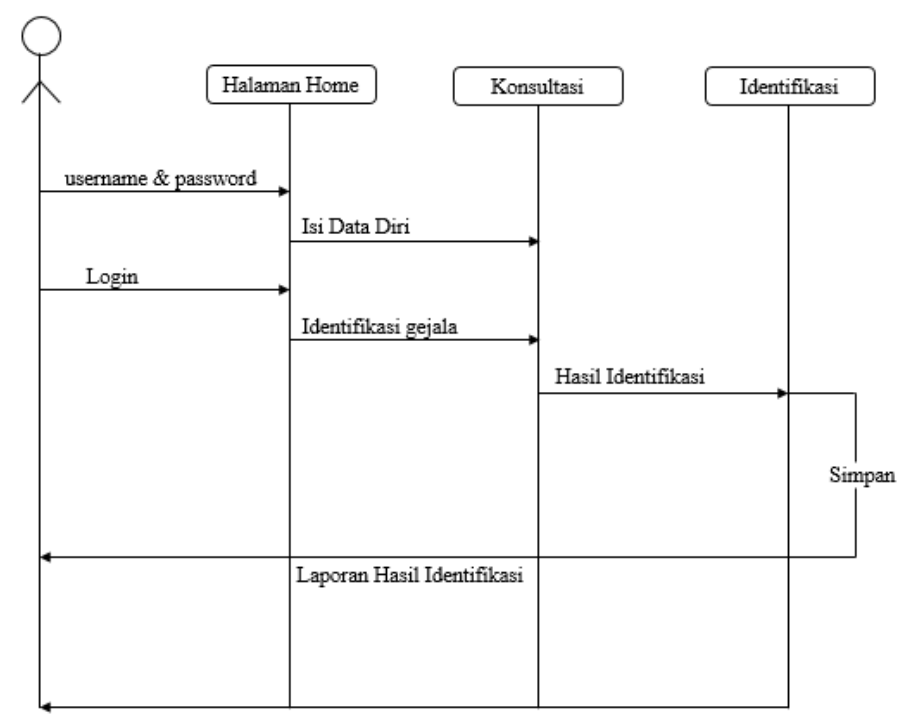

Gambar 4. Sequence Diagram

\section{B. Desain User Interface}

\section{Halaman identifikasi gejala}

Pada halaman ini menampilkan halaman identifikasi gejala insomnia yang harus dipilih oleh pengguna sesuai dengan gejala yang sudah disediakan oleh sistem pakar.

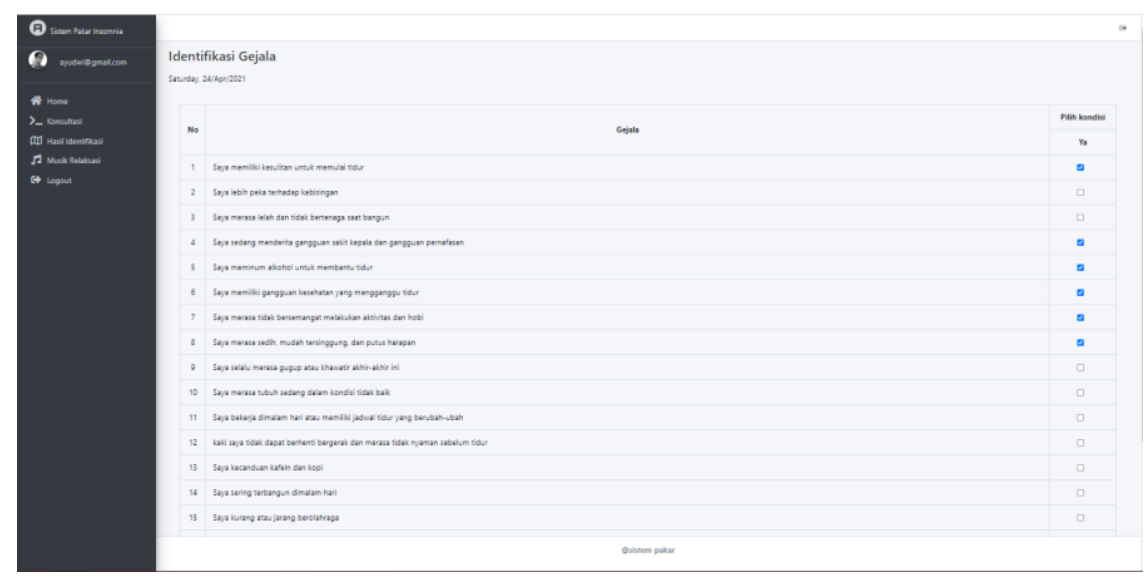

Gambar 5. Halaman Identifikasi Gejala Sistem Pakar

\section{Halaman hasil identifikasi}

Pada halaman ini menampilkan hasil identifikasi atau kesimpulan yang dihasilkan oleh sistem setelah pengguna memilih gejala yang dialami atau berkonsultasi. Pengguna bisa mengetahui jenis penyakit insomnia apa yang sedang dialami. Dengan demikian Pengguna bisa melakukan konsultasi dengan seorang ahli untuk melakukan penanganan lanjut. 
Procedia of Engineering and Life Science Vol. 1. No. 2 Juni 2021

Seminar Nasional \& Call Paper Fakultas Sains dan Teknologi (SENASAINS 2nd)

Universitas Muhammadiyah Sidoarjo

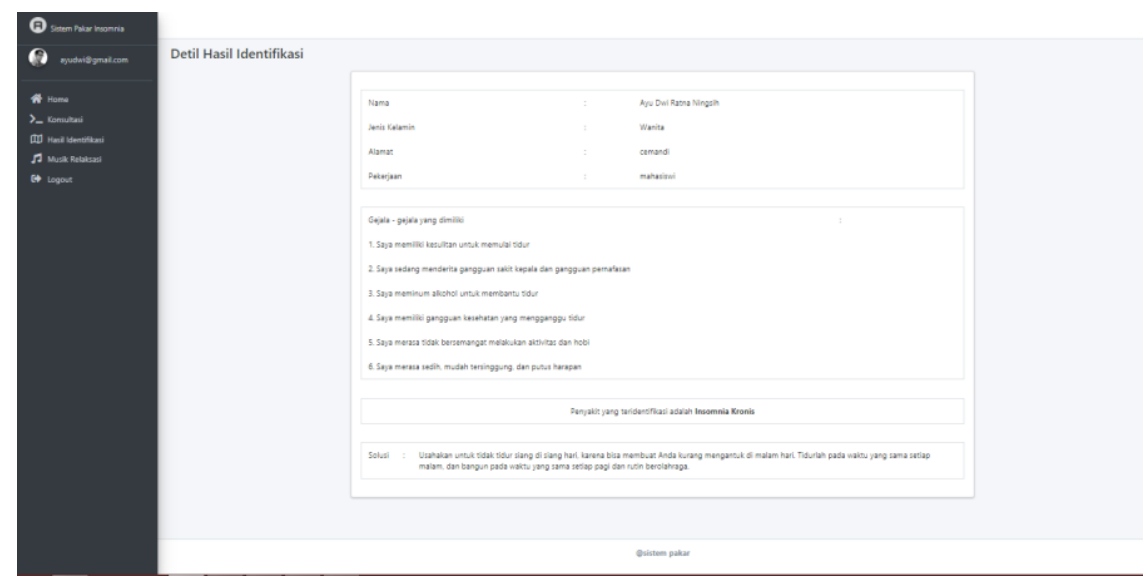

Gambar 6. Halaman Hasil Identifikasi

Halaman musik relaksasi

Halaman ini menampilkan sebuah file musik relaksasi yang digunakan untuk membantu user dalam melakukan meditasi atau meredam masalah insomnia yang sedang dialami.

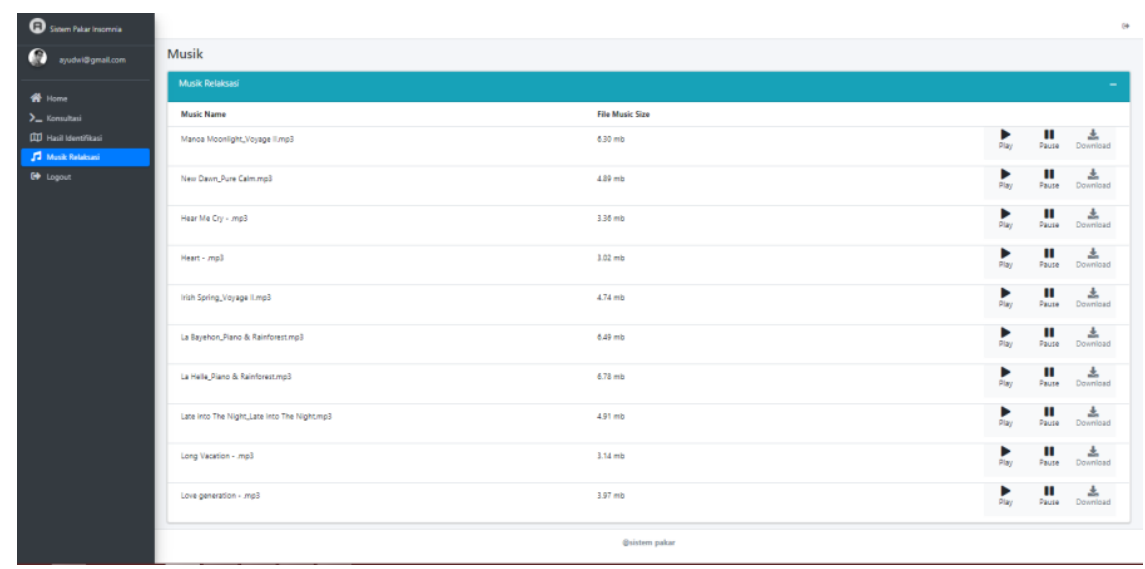

Gambar 7. Halaman Musik Relaksasi

\section{KESIMPULAN}

Dari hasil penelitian Sistem Pakar untuk Mengidentifikasi masalah insomnia pada orang dewasa menggunakan metode forward chaining dapat beberapa kesimpulan sebagai berikut : (1) Perancangan dan pembangunan sistem pakar dapat mempermudah memberikan informasi berupa kesimpulan atau hasil identifikasi tentang pengguna yang terkena penyakit insomnia berdasarkan fakta-fakta yang diberikan, selain itu sistem pakar juga memberikan solusi terkait gejala yang diderita layaknya seorang pakar, sehingga hal ini bisa menjadi acuan pengguna untuk melakukan konsultasi lebih lanjut ke dokter.

\section{UCAPAN TERIMA KASIH}

Dengan penelitian ini, penulis mengucapkan terimakasih banyak kepada semua pihak terkait yang sudah membantu dalam melakukan penulisan artikel ilmiah yang berjudul "Sistem Pakar untuk Mengidentifikasi masalah Insomnia pada orang dewasa menggunakan metode Forward Chaining".

\section{REFERENSI}

[1] Dahria, M. (2011) 'Pengembangan Sistem Pakar Dalam Membangun Suatu Aplikasi', Jurnal Saintikom, 10(3), pp. 199-205.

[2] Diponegoro, U., Kedokteran, F. and Diponegoro, U. (2012) 'PENGALAMAN MAHASISWA YANG MENGALAMI INSOMNIA Staf pengajar Departemen Jiwa dan Komunitas Program Studi Ilmu Pendahuluan 
Procedia of Engineering and Life Science Vol. 1. No. 2 Juni 2021

Seminar Nasional \& Call Paper Fakultas Sains dan Teknologi (SENASAINS 2nd)

Universitas Muhammadiyah Sidoarjo

Insomnia adalah kesulitan memulai dan mempertahankan tidur ( Lopez, Penelitian yang disampaikan oleh DiMatteo dan Martin pada tahun 20', Jurnal Nursing Studies, 1(1), pp. 231-236.

[3] Fadhli, M. (2011) 'Sistem Pakar untuk Mendiagnosa Penyakit Kucing Menggunakan Metode Backward Chaining',(1994), pp. 134-139.

[4] Firman, A. et al. (2016) 'Sistem Informasi Perpustakaan Online Berbasis Web', 5(2).

[5] Muniar Ashari, A. Y. A. (2015) 'Penerapan Sistem Pakar dalam Mendiagnosa Hama dan Penyakit Tanaman Jarak Pagar dengan Metode Forward Chaining', Jurnal Inspiration, (Vol 5, No 2 (2015): Jurnal Inspiration Tahun V Edisi 2), pp. 89-97. Available at: http://jurnal.akba.ac.id/index.php/inspiration/article/view/64.

[6] Putri, A. D. and Pratama, D. (2017) 'Sistem Pakar Mendeteksi Tindak Pidana Cybercrime Menggunakan Metode Forward Chaining Berbasis Web Di Kota Batam', Edik Informatika, 3(2), pp. 197-210.

[7] Rafknowledge. (2014) 'Insomnia dan Gangguan Tidur'. Elex Media Komputindo. Jakarta

[8] Rianjani, E., Nugroho, H. A. and Astuti, R. (2016) 'Kejadian Insomnia Berdasarkan Karakteristik Dan Tingkat Kecemasan Pada Lansia Di Panti Wredha Pucang Gading Semarang', Jurnal Keperawatan, 4(2), pp. 194-209.

[9] Sma, D. I., Manado, N. and Wowiling, F. (2015) 'HUBUNGAN DURASI PENGGUNAAN MEDIA SOSIAL DENGAN KEJADIAN INSOMNIA PADA REMAJA', 3.

[10] Studi, P. et al. (2015) 'PEDOMAN PRAKTIKUM STANDAR WEB'.

[11] Sumirta, I. N. (2013) '( INSOMNIA ) PADA LANSIA'. 